\title{
PERDAS DE NITROGÊNIO VIA SUPERFÍCIE E SUBSUPERFÍCIE EM SISTEMA DE SEMEADURA DIRETA
}

\author{
Oromar João Bertol*, Nivaldo Eduardo Rizzi**, Nerilde Favaretto***, Osmir José Lavoranti**** \\ *Eng. Agrônomo, Dr., EMATER - PR - oromarbertol@ig.com.br \\ **Eng. Florestal, Dr., Depto. de Engenharia e Tecnologia Florestal da UFPR - niva@floresta.com.br \\ ***Enga . Agrônoma, Ph.D., Depto. de Solos e Engenharia Agrícola da UFPR - nfavaretto@ufpr.br \\ ****Estatístico, Dr., EMBRAPA-CNPF, Depto. de Estatística da UFPR - osmir@cnpf.embrapa.br \\ Recebido para publicação: 18/03/2005 - Aceito para publicação: 22/12/2005
}

\begin{abstract}
Resumo
Perdas de nitrogênio via superficie e subsuperficie em sistema de semeadura direta. O nitrogênio (N) é o elemento utilizado em maior quantidade na produção agrícola, estando, portanto, sujeito a perdas acentuadas que afetam a qualidade das águas. Na agricultura, em particular nas lavouras conduzidas sob o sistema de semeadura direta, as perdas tem se mostrado preocupantes em decorrência da concentração desse elemento na superfície do solo, o que facilita o seu transporte através da enxurrada. No entanto, a adoção de medidas que aumentem a infiltração da enxurrada poderá reter na matriz do solo as diferentes formas de $\mathrm{N}$. O objetivo deste trabalho foi avaliar, sob condições de semeadura direta e adubação mineral e orgânica, as perdas de diferentes formas de $\mathrm{N}$ na enxurrada (através de chuva simulada) e na água percolada (através de colunas indeformadas de solo). O uso do dejeto suíno resultou uma maior concentração de $\mathrm{N}$ total na enxurrada, com exceção da chuva de menor intensidade. Independentemente dos tratamentos, a concentração de $\mathrm{N}$ total na enxurrada, bem como no sobrenadante, foi maior na chuva inicial quando comparada com a chuva final, mesmo sendo esta a de maior intensidade. Para o N-NH 4 e N-NO adubo mineral, ocasionou as maiores concentrações na enxurrada. No entanto, o oposto foi observado na lixiviação, em que o nitrogênio apresentou as menores concentrações em todos os volumes de poros. A matriz do solo reteve com mais eficiência o $\mathrm{N}_{-} \mathrm{NH}_{4}$ do que o $\mathrm{N}-\mathrm{NO}_{3}$, sendo que todo o N$\mathrm{NO}_{3}$ aplicado foi lixiviado. No tratamento com dejeto suíno, a perda dos elementos na lixiviação foi mais prolongada do que no tratamento com fertilizante mineral.

Palavras-chave: Adubação mineral e orgânica; enxurrada; infiltração; qualidade da água.
\end{abstract}

\begin{abstract}
Nitrogen losses by surface and subsurface drainage from no-till system. Nitrogen $(\mathrm{N})$ is an element used in large amount in the agricultural production, being therefore, subjected to great losses affecting water quality. In agriculture, especially in no till system, nitrogen loss is a concern due to the high concentration of this element on the soil surface, what facilitates the transport by runoff. However, the adoption of measures that increase infiltration could hold in the soil bulk the different forms of $\mathrm{N}$. The objective of this work was to evaluate, in no till system under mineral and organic fertilization, the losses of different forms of $\mathrm{N}$ in the runoff by rainfall simulation and the leached water by undisturbed soil column. The use of the swine manure resulted higher concentration of runoff total N, except in the lower intensity rainfall. However, independent of the treatments, the concentration of the runoff total $\mathrm{N}$ as well as the supernatant runoff total nitrogen was higher in the initial rainfall compared to final rainfall, even being this the highest rainfall intensity. For runoff $\mathrm{NH}_{4}-\mathrm{N}$ and $\mathrm{NO}_{3}-\mathrm{N}$, the swine manure compared with the mineral fertilizer caused the higher concentration. However, the opposite was observed in the leached water, which presented the smaller concentration in all the pore volumes. The soil bulk held more efficiently the $\mathrm{NH}_{4}-\mathrm{N}$ than $\mathrm{NO}_{3}-\mathrm{N}$. All the applied $\mathrm{NO}_{3}-\mathrm{N}$ was leached out. In the treatment with swine manure, the leaching of the elements was slower compared with the mineral fertilizer treatment.

Keywords: Mineral and organic fertilization; runoff; infiltration; water quality.
\end{abstract}




\section{INTRODUÇÃO}

Com o advento da chamada agricultura moderna, observa-se um aumento no emprego não só de adubos minerais, mas também de orgânicos, dentre os quais os dejetos de animais. Melhorar o padrão de fertilidade do solo e dar um destino a esses dejetos são objetivos básicos, no entanto, a reciclagem de nutrientes através da aplicação de dejetos de animais pode causar danos ao ambiente. Dentre os nutrientes com potencial poluidor encontra-se o nitrogênio $(\mathrm{N})$, que é um nutriente essencial para as plantas e o mais aplicado na agricultura (Smith et al., 1990). Esse elemento, em elevada concentração na água, contribui com a eutrofização e também afeta a saúde humana (Daniel et al., 1998).

A eutrofização, uma excessiva concentração de nutrientes que resulta em alto crescimento da biota aquática e restringe o uso da água em diversas atividades, é principalmente limitada por fósforo (P) em água doce. O nitrogênio está também associado com a aceleração da eutrofização, mas devido à capacidade de algumas plantas aquáticas de fixar nitrogênio atmosférico, o fósforo tem recebido maior atenção no estudo desse fenômeno (Correll, 1998; Daniel et al., 1998). Em relação à saúde humana, a concentração de nitrato nas águas deve ser regulada, por causar a doença conhecida como metahemoglobinemia ou síndrome do bebê azul. A concentração máxima de nitrogênio na forma de nitrato $\left(\mathrm{N}-\mathrm{NO}_{3}\right)$ na água de consumo humano no Brasil, bem como nos Estados Unidos da América, é limitada em $10 \mathrm{mg} \mathrm{L}^{-1}$ (aproximadamente $45 \mathrm{mg} \mathrm{L}^{-1}$ de $\mathrm{NO}_{3}$ ) (Tundisi, 2003; USEPA, 1999). Esse limite máximo é também utilizado em águas doces de classe 1, 2 e 3, de acordo com BRASIL (1986).

Muitos estudos têm envolvido a qualidade da água superficial e a erosão do solo (Cassol et al., 2002; Pote et al., 1999; Gburek e Sarpley, 1998; Sharpley, 1995; Sharpley et al., 1981), mostrando que um dos principais mecanismos de perda de nutrientes dos ambientes é através da erosão hídrica do solo, uma vez que eles são transportados pela enxurrada, associados aos sedimentos ou dissolvidos na água (Gburek e Sharpley, 1998; Sharpley et al., 1992). Essas perdas iniciam quando a chuva interage com a fina camada de solo, liberando os nutrientes do solo e dos resíduos culturais (Sharpley, 1985). No sistema de semeadura direta, a concentração e distribuição de nutrientes no solo diferem em relação ao convencional, observando-se um acúmulo de nutrientes na superfície, pela não-inversão da camada superior do solo (Ismail et al., 1994). A concentração de nutrientes na superfície torna-se ainda mais acentuada quando os fertilizantes são aplicados sem incorporação ao solo (Cassol et al., 2002; Soileau et al., 1994), tornando-se um potencial de perda de nutrientes via escoamento superficial, principalmente na forma solúvel.

A perda de nitrogênio via enxurrada pode ocorrer tanto na forma solúvel como na forma particulada ( $\mathrm{N}$ orgânico $+\mathrm{N}$ mineral ligado ao sedimento). As formas solúveis de nitrogênio, nitrato $\left(\mathrm{NO}_{3}^{-}\right)$e amônio $\left(\mathrm{NH}_{4}^{+}\right)$, mas principalmente o nitrato, são normalmente encontradas em baixas concentrações no escoamento superficial, enquanto que o $\mathrm{N}$ particulado é a principal forma de $\mathrm{N}$ transportado via superfície (Smith et al., 1990; Sharpley et al., 1987).

Embora o nitrogênio tenha uma grande mobilidade no solo, particularmente na forma de $\mathrm{N}-\mathrm{NO}_{3}$ (Sharpley et al., 1993), estando, portanto, sujeito a uma maior perda pela lixiviação, igualmente pode ser retido pela matriz do solo, sobretudo quando este é altamente intemperizado. As cargas (CTC e CTA) do solo podem ser preenchidas pela adsorção de diferentes formas de nitrogênio, como o N-NO $\mathrm{N}_{3}$ o N-NH (Sharpley et al., 1993; Smith et al., 1990), principalmente este último, uma vez que tem a suscetibilidade à perda reduzida pela adsorção no complexo de trocas de cátions. Dentro desse enfoque, é desejável que se tomem medidas para que a enxurrada se infiltre no solo ao invés de escoar superficialmente. Assim, promove-se o controle da erosão hídrica e a retenção na matriz do solo dos nutrientes presentes na enxurrada, evitando o movimento deles para locais sensíveis - tais como corpos de água -, contribuindo ainda no suprimento de nutrientes para as plantas.

Simplificadamente, pode-se dizer que a água precipitada pode seguir dois caminhos: escoar superficialmente ou subsuperficialmente. Além das características intrínsecas do solo, várias práticas de contenção do escoamento superficial e sistemas de uso e manejo do solo interferem nesse processo. Entre os sistemas de manejo do solo, a semeadura direta tem se mostrado eficiente no controle da perda de solo por manter os resíduos vegetais na superfície (Amaral, 2002; Eghball e Gilley, 1999). Estes, quando na superfície, protegem o solo contra o efeito desagregador das gotas da chuva, sendo um meio eficaz para reduzir a concentração de sedimentos na enxurrada (Meyer et al., 1970). Isso faz com que a semeadura direta apresente maior eficiência no controle das perdas de solo do que de água e, em conseqüência, as 
perdas de nutrientes, nesse sistema, tenham uma relação mais direta com a perda de água (Cassol et al., 2002). Práticas que reduzem o escoamento superficial e a erosão, como sistemas de terraceamento, podem diminuir a perda superficial de $\mathrm{N}$ solúvel e particulado (Ownes, 1994). Ao possibilitar que a enxurrada se acumule no canal e infiltre no solo, o terraço auxilia a manutenção de determinados nutrientes na matriz do solo e evita os prejuízos ambientais pela não-chegada destes aos mananciais de água.

Este trabalho foi realizado com o objetivo de avaliar o efeito da adubação orgânica e mineral em condições de semeadura direta sobre o transporte de nitrogênio na forma de amônio e nitrato, via escoamento superficial e subsuperficial, bem como a retenção desse elemento no solo.

\section{MATERIAL E MÉTODOS}

Este trabalho foi desenvolvido na região oeste do Estado do Paraná, no Campus da Faculdade de Agronomia da UNIOESTE, sendo constituído por dois experimentos, um a campo, com chuva simulada, e outro em laboratório, com lixiviação em colunas de solo indeformado. A região possui clima subtropical, de verões quentes, com precipitação média anual de $1700 \mathrm{~mm}$. Segundo Köepen, o clima da região é do tipo Cfa. O solo da área experimental é um Latossolo Vermelho Eutroférico, sendo suas características apresentadas na Tabela 1. A densidade do solo, densidade de partícula e porosidade total são de $1,29 \mathrm{~g} \mathrm{~cm}^{-3}, 2,74 \mathrm{~g} \mathrm{~cm}^{-3}$ e $51,61 \%$, respectivamente. A declividade média é $0,045 \mathrm{~m} \mathrm{~m}^{-1}$. As densidades do solo e de partícula foram determinadas pelo método do anel e balão volumétrico, respectivamente, de acordo com EMBRAPA (1997). A porosidade total foi obtida através da saturação por volume (EMBRAPA, 1997). Nos últimos cinco anos, a área experimental foi manejada através do sistema de semeadura direta.

Tabela 1. Características físicas, químicas e mineralógicas do solo (Latossolo Vermelho Eutroférico) da área experimental.

Table 1. Physical, chemical and mineralogical characterization of the soil (Latossolo Vermelho Eutroférico) from the experimental area.

\begin{tabular}{|c|c|c|c|c|c|c|c|c|c|c|c|c|c|}
\hline \multirow{2}{*}{ Camada } & \multicolumn{13}{|c|}{ Características } \\
\hline & $\mathbf{A} \mathbf{R}^{1}$ & $\mathbf{A g}^{2}$ & $\mathbf{A f ^ { 3 }}$ & $\mathrm{Si}^{4}$ & $\mathrm{CO}^{5}$ & $\mathbf{P}$ & $\mathbf{K}$ & $\mathbf{C a}$ & Mg & Al & pH & $\mathrm{Ct}^{6}$ & $\mathrm{He}^{+}$ \\
\hline & ------ & ----- & $\mathrm{kg}^{-1}-$ & - & $-\mathrm{I}^{-} \mathrm{m \xi}$ & $\mathrm{kg}^{-1}$ & & $--\mathrm{mm}$ & $\mathrm{kg}^{-1}$ & - & & --- & 10----- \\
\hline $0-2,5 \mathrm{~cm}$ & 682,9 & 39,1 & 58,8 & 219,2 & 21,4 & 65,3 & 8,15 & 68,3 & 36,8 & 0,0 & 6,25 & 68,1 & 21,0 \\
\hline $2,5-20 \mathrm{~cm}$ & 734,7 & 37,8 & 43,1 & 184,4 & 11,9 & 52,5 & 2,75 & 41,5 & 20,5 & 0,0 & 5,33 & 58,3 & 21,6 \\
\hline
\end{tabular}

Argila; ${ }^{2}$ Areia grossa; ${ }^{3}$ Areia fina; ${ }^{4}$ Silte; $;{ }^{5}$ Carbono Orgânico; ${ }^{6}$ Caulinita; ${ }^{7} \mathrm{Hematita}$. Granulometria determinada pelo método do densímetro (EMBRAPA, 1997). C orgânico através do método colorimétrico; P e K pelo método Mehlich; $\mathrm{Ca}, \mathrm{Mg}$ e $\mathrm{Al}$ extraídos com KCl 1N; e pH CaCl 2 0,01M (Pavan et al., 1992); Hematita por extração com DCB (Mehra e Jackson, 1960); Caulinita foi determinada conforme Melo (1998).

\section{Perdas de nitrogênio na enxurrada}

$\mathrm{Na}$ implantação do experimento com chuva simulada, efetuou-se uma operação de semeadura realizada no sentido da maior declividade do terreno. Essa condição foi simulada por representar o que ocorre em lavouras sem sistema de terraceamento e por criar uma condição crítica de transporte de sedimentos por enxurrada. Após a operação com a semeadora, constituída por sulcadores distantes $40 \mathrm{~cm}$ entre si, implantaram-se as parcelas, todas localizadas dentro da área de incidência do simulador de chuva. Cada parcela com área de $0,9603 \mathrm{~m}^{2}$ continha uma calha autolimpante e um reservatório para coletar a enxurrada proveniente das chuvas simuladas.

Os tratamentos com quatro repetições foram os seguintes: dejeto líquido de suíno aplicado na superfície na dosagem de $60 \mathrm{~m}^{3} \mathrm{ha}^{-1}$ (D), adubo mineral, $200 \mathrm{~kg} \mathrm{ha}^{-1}$ do formulado 2-20-20 $\left(\mathrm{N}-\mathrm{P}_{2} \mathrm{O}_{5}-\mathrm{K}_{2} \mathrm{O}\right)$ distribuído na superfície (NPK) e sem adubo (T). O dejeto de suíno foi coletado em esterqueira convencional de alimentação contínua e amostrado para determinar os teores de $\mathrm{N}$ total e matéria seca. $\mathrm{O}$ adubo mineral também foi analisado com relação ao $\mathrm{N}$ total. $\mathrm{O}$ dejeto apresentou 3,9 e $31,9 \mathrm{~g} \mathrm{~kg}^{-1} \mathrm{de} \mathrm{N}^{\mathrm{N}}$ total e matéria seca, respectivamente, o que correspondeu a uma aplicação de $234 \mathrm{~kg} \mathrm{ha}^{-1}$ de N. O adubo mineral apresentou $3,13 \mathrm{~g} \mathrm{~kg}^{-1}$ de $\mathrm{N}$ total, correspondendo a uma aplicação de $6,2 \mathrm{~kg} \mathrm{ha}^{-1} \mathrm{de} \mathrm{N}$. As doses de fertilizantes e conseqüentemente de nitrogênio foram escolhidas por serem as de maior aplicação nas lavouras por produtores rurais. 
Após 16 horas da aplicação dos fertilizantes, iniciou-se a chuva simulada, através de um simulador de braços rotativos (Swanson, 1975). As quatro chuvas tiveram as seguintes características e seqüência: chuva de umedecimento, com intensidade de $56,77 \mathrm{~mm} \mathrm{~h}^{-1}$ e duração de 38 minutos; chuva $\mathrm{C} 1$, com intensidade de $72,22 \mathrm{~mm} \mathrm{~h}^{-1}$ e duração de 20 minutos, aplicada 30 minutos após a chuva de umedecimento; chuva $\mathrm{C} 2$, com intensidade de $63,24 \mathrm{~mm} \mathrm{~h}^{-1}$ e duração de 20 minutos, aplicada 30 minutos após a chuva $\mathrm{C}$, e chuva $\mathrm{C} 3$, com intensidade de $116,89 \mathrm{~mm} \mathrm{~h}^{-1}$ e duração de 20 minutos, aplicada 30 minutos após a chuva $\mathrm{C} 2$.

Ao final de cada chuva $(\mathrm{C} 1, \mathrm{C} 2$ e $\mathrm{C} 3)$, retirou-se a amostra da enxurrada, a qual foi filtrada em filtro de 0,45 $\mu \mathrm{m}$. Após a filtragem, determinou-se a concentração de $\mathrm{N}^{-\mathrm{NO}_{3}}$ e $\mathrm{N}-\mathrm{NH}_{4}$ solúvel. Coletaram-se também amostras não filtradas para determinar a concentração do $\mathrm{N}$ total. $\mathrm{O}$ restante de cada enxurrada foi mantido no respectivo reservatório em repouso durante 24 horas, para permitir a decantação dos sedimentos. Após esse período, retirou-se uma amostra da água sobrenadante com os sedimentos que permaneceram em suspensão, para determinar o $\mathrm{N}$ total do sobrenadante.

Optou-se por separar, para fins de análise, o sobrenadante da enxurrada total, considerando que quando esta chega a um curso de água, não haverá a deposição de todo o sedimento transportado. As partículas suspensas na coluna de água juntamente com os elementos químicos em solução serão transportadas do solo para a água, constituindo-se em um potencial de eutrofização para a porção do rio a jusante do ponto que recebeu a enxurrada. Assim, pode-se dizer que após certo período de repouso, a enxurrada apresenta um sedimento de fundo e um sobrenadante contendo elementos químicos em solução e partículas finas em suspensão. Por outro lado, essas partículas finas, em virtude de serem compostos orgânicos e argilominerais, apresentam grande atividade, sendo altamente enriquecidas de nutrientes (Távora et al., 1985).

$\mathrm{O} \mathrm{N}-\mathrm{NO}_{3}$ solúvel foi determinado por colorimetria em espectrofotômetro sob comprimento de onda de $221 \lambda$ de acordo com a metodologia modificada de Miyazawa et al. (1985) e Norman e Stucki (1981). O N-NH 4 solúvel foi determinado em espectrofotômetro, sob comprimento de onda de $640 \lambda$ pelo método do fenato de acordo com APHA (1995). O $\mathrm{N}$ total da enxurrada e do sobrenadante foi determinado pelo método Kjeldahl modificado de Westerman (1990), no entanto, considerando que esse método não inclui o nitrato (Bremner, 1996), obteve-se o $\mathrm{N}$ total tanto da enxurrada como do sobrenadante pelo somatório do $\mathrm{N}$ total via Kjeldahl com o N-NO 3 solúvel da enxurrada.

\section{Perdas de nitrogênio via lixiviação}

Foram coletadas doze colunas de solo, amostras indeformadas, com altura de solo de $20 \mathrm{~cm}$ e diâmetro de 20,3 cm. As colunas (tubos de PVC) apresentavam $25 \mathrm{~cm}$ de altura, 20,3 cm de diâmetro interno e $0,9 \mathrm{~cm}$ de espessura de parede. Após a coleta, as colunas foram levadas para laboratório e colocadas sobre uma esteira de papelão durante 54 dias para eliminar a umidade até um ponto que proporcionasse a contração do solo. Esse processo teve como propósito criar um espaço entre a parede interna do tubo e a coluna de solo. Esse espaço teve a porção superior vedada com silicone, em dois centímetros, para impedir que a água formasse um fluxo preferencial nesse espaço.

As colunas foram colocadas sobre um prato de plástico com o fundo recoberto por uma camada de $0,5 \mathrm{~cm}$ de sílica neutra e dotado de um dreno na parte inferior. A seguir, o prato contendo a coluna foi levado até uma bancada. Fez-se então a obstrução do dreno com silicone para permitir o umedecimento das colunas com o objetivo de eliminar o ar do solo e proporcionar a expansão do solo para que este ocupasse novamente o espaço existente entre a coluna de solo e a parede interna do tubo. Para tanto, colocou-se água nos pratos até uma altura de lâmina de $3 \mathrm{~cm}$, para que, através do movimento ascendente, a água ocupasse os microporos. A lâmina de água foi mantida por 12 horas, sendo drenada após esse período. Esse procedimento foi repetido duas vezes.

Os tratamentos com quatro repetições foram os seguintes: dejeto líquido de suíno na dosagem de $150 \mathrm{~m}^{3} \mathrm{ha}^{-1}(\mathrm{D})$, adubo mineral solúvel na forma de $\mathrm{NH}_{4} \mathrm{NO}_{3}, \mathrm{NH}_{4} \mathrm{H}_{2} \mathrm{PO}_{4}$ e $\mathrm{KCl}$ na quantidade de $140 \mathrm{~kg}$ $\mathrm{ha}^{-1}$ de N (NPK) e sem adubo (T). A mesma quantidade de água que o dejeto de suíno continha também foi aplicada nas colunas com o tratamento NPK e T, sendo os fertilizantes aplicados na superfície das colunas. As doses de dejeto suíno e adubo mineral, neste experimento, foram superiores às aplicadas no experimento de campo com chuva simulada. Isso se justifica considerando-se que o objetivo do experimento com colunas de solo foi avaliar a capacidade da matriz do solo em reter elementos minerais 
numa condição onde a enxurrada acumulada apresenta uma elevada concentração de nutrientes em solução, como no canal de um terraço.

$\mathrm{O}$ dejeto líquido de suíno foi coletado em esterqueira convencional de alimentação contínua e foram retiradas amostras para a determinação de $\mathrm{N}$ total e matéria seca. As análises apresentaram os valores de 4,4 $\mathrm{g} \mathrm{kg}^{-1}$ e 63,3 $\mathrm{g} \mathrm{kg}^{-1}$ de $\mathrm{N}$ total e matéria seca, respectivamente, o que correspondeu a uma aplicação de $660 \mathrm{~kg} \mathrm{ha}^{-1}$ de $\mathrm{N}$ total.

A percolação da água deionizada através das colunas de solo foi realizada por gotejamento aplicando-se uma taxa de $2,2 \mathrm{ml}$ por minuto. Para melhor distribuição e uniformidade na percolação da água, esta foi aplicada em três pontos sobre um feltro colocado na superfície do solo. A água foi coletada em cinco turnos, sem intervalo de tempo entre eles, correspondendo a três volumes de poros. O volume de água percolada correspondente ao primeiro volume de poros foi subdividido em três turnos (T1A, T1B, T1C) e os dois últimos turnos (T2 e T3) tiveram o volume de água coletada em cada amostra igual a um volume de poros. Tendo em vista que a porosidade total do solo era de 51,61\% e considerando-se as dimensões da coluna (20,3 cm de diâmetro e $20 \mathrm{~cm}$ de altura), obteve-se o volume total de poros de 3340 $\mathrm{cm}^{3}$ em cada coluna. Portanto, o volume das três primeiras foi de $1114 \mathrm{ml}$ cada e das duas últimas de $3340 \mathrm{ml}$ cada, ou seja, 1/3, 2/3, 1, 2 e 3 volume de poros, respectivamente. A quantidade total de água aplicada correspondeu a uma altura de lâmina de água de 309,6 mm. A água percolada foi conduzida através do dreno para um reservatório colocado abaixo de cada coluna. Para cada uma das amostras, retirou-se uma alíquota de $200 \mathrm{ml}$, sendo esta filtrada em filtro de $0,45 \mu \mathrm{m}$, para análise da concentração de $\mathrm{N}-\mathrm{NH}_{4}$ e $\mathrm{N}-\mathrm{NO}_{3}$ solúvel. Os teores $\mathrm{N}_{-} \mathrm{NO}_{3}$ e $\mathrm{N}-\mathrm{NH}_{4}$ solúvel foram determinados através da mesma metodologia empregada para determinar os teores desses elementos na água filtrada da enxurrada.

\section{Delineamento experimental}

O delineamento para ambos os experimentos foi o inteiramente aleatorizado, com distribuição fatorial dos tratamentos, ou seja, dejeto líquido de suíno aplicado na superfície (D), adubo mineral (NPK) e testemunha $(\mathrm{T})$ versus chuva $1(\mathrm{C} 1)$, chuva $2(\mathrm{C} 2)$ e chuva $3(\mathrm{C} 3)$, para o experimento a campo com chuva simulada, e versus T1A, T1B, T1C, T2 e T3 para o experimento em laboratório com lixiviação em colunas de solo indeformado. As comparações múltiplas foram realizadas por contrastes ortogonais do teste $\mathrm{F}$, sendo que a análise estatística dos resultados foi feita pelo programa SAS.

\section{RESULTADOS E DISCUSSÃO}

\section{Perda de nitrogênio na enxurrada \\ Concentração de nitrogênio total na enxurrada}

A utilização do dejeto de suíno proporcionou uma maior concentração de nitrogênio total (NT) na enxurrada das chuvas $\mathrm{C} 1$ e $\mathrm{C} 3$ do que o adubo mineral (Tabela 2). O resultado da chuva $\mathrm{C} 1$ reflete a grande quantidade de $\mathrm{N}$ aplicada no tratamento dejeto de suíno, o qual foi cerca de 38 vezes maior do que a quantidade de $\mathrm{N}$ aplicado na forma de adubo mineral. A chuva $\mathrm{C} 2$ proporcionou enxurrada com concentrações de NT iguais entre os tratamentos (Tabela 2), provavelmente devido à diminuição desse elemento no dejeto suíno após a chuva $\mathrm{C} 1$ e à menor capacidade da chuva $\mathrm{C} 2 \mathrm{em}$ removê-lo e transportálo, devido à menor intensidade. Já a maior intensidade da chuva C3 provavelmente se traduziu em uma maior capacidade para remover e transportar NT das parcelas com dejeto, o que explica a maior concentração do elemento na enxurrada desse tratamento, em relação aos demais tratamentos. Os tratamentos NPK e T apresentaram concentrações iguais de NT na enxurrada, provavelmente devido à pequena dose de $\mathrm{N}$ aplicada como adubo mineral e à quantidade elevada do elemento presente no solo em condições naturais, proporcionado pelo sistema de semeadura direta (Sharpley et al., 1994).

Os resultados mostram que a proporção de NT aplicado no tratamento com dejeto suíno e adubo mineral (38 vezes) não teve relação proporcional na concentração de NT na enxurrada desses dois tratamentos, os quais apresentaram uma proporção inferior a duas vezes. Os seguintes fatores podem explicar esse comportamento: a) o tempo (16 horas) transcorrido entre a colocação dos adubos e a aplicação das chuvas possibilitou que o dejeto, por ser líquido, penetrasse no solo, ficando menos sujeito à remoção e transporte; b) todo o volume da chuva de umedecimento e uma porção inicial da chuva $\mathrm{C} 1$ não produziram enxurrada, infiltrando-se no solo e, assim, lixiviando para camadas mais profundas uma porção significativa do $\mathrm{N}$ presente no dejeto. 
Na comparação entre as chuvas dentro de cada tratamento, para o tratamento D a concentração de NT na enxurrada da chuva $\mathrm{C} 1$ foi em torno de $50 \%$ maior do que as duas últimas chuvas, as quais não diferiram entre si. No tratamento NPK, as concentrações foram iguais na enxurrada das duas primeiras chuvas e superiores à chuva $\mathrm{C} 3$ (Tabela 2). Os resultados indicam que, independentemente da fonte de $\mathrm{N}$ utilizado para adubação em superfície, a remoção de $\mathrm{N}$ total foi muito maior nas primeiras chuvas, em particular quando o adubo utilizado foi o dejeto suíno, mostrando que tanto a disponibilidade do $\mathrm{N}$ como a intensidade da chuva influenciaram na concentração de $\mathrm{N}$ total da enxurrada. Cassol et al. (2002) obtiveram resultados semelhantes ao constatarem que as concentrações de nutrientes na enxurrada foram maiores por ocasião da aplicação da primeira chuva simulada, diminuindo nas demais chuvas aplicadas. No tratamento T não houve diferença na concentração do NT na enxurrada gerada pelas diferentes chuvas (Tabela 2).

Tabela 2. Contraste de médias da concentração de $\mathrm{N}$ total (NT) na enxurrada em três chuvas simuladas $(\mathrm{C} 1, \mathrm{C} 2, \mathrm{C} 3)$ aplicadas seqüencialmente nos tratamentos dejeto de suíno (D), adubo mineral (NPK) e testemunha (T).

Table 2. Mean contrast of runoff total N (NT) concentration in three simulated rainfall (C1, C2, C3) sequentially applied on the swine manure (D), mineral fertilizer (NPK) and control (T) treatments.

\begin{tabular}{|c|c|c|c|c|c|}
\hline \multirow{2}{*}{ Chuvas } & \multicolumn{3}{|c|}{ Tratamento } & \multicolumn{2}{|c|}{ Contrastes } \\
\hline & D & NPK & $\mathbf{T}$ & T vs D, NPK & D vs NPK \\
\hline & \multicolumn{3}{|c|}{------------------ mg L'1 de N Total------------------ } & \multicolumn{2}{|c|}{$\operatorname{Pr}>\mathrm{F}$} \\
\hline $\mathrm{C} 1$ & $62,79 \pm 0,95$ & $39,38 \pm 2,80$ & $35,49 \pm 4,50$ & 0,0027 & 0,0005 \\
\hline $\mathrm{C} 2$ & $40,75 \pm 2,45$ & $37,58 \pm 2,47$ & $36,46 \pm 2,75$ & 0,4110 & 0,4050 \\
\hline $\mathrm{C} 3$ & $38,46 \pm 1,55$ & $30,62 \pm 2,75$ & $28,50 \pm 0,70$ & 0,0010 & 0,0004 \\
\hline Contrastes & & $\operatorname{Pr}>F$ & & & \\
\hline $\mathrm{C} 1$ vs $\mathrm{C} 2, \mathrm{C} 3$ & $<0,0001$ & 0,0790 & 0,4450 & & \\
\hline $\mathrm{C} 2$ vs $\mathrm{C} 3$ & 0,3760 & 0,0490 & 0,1010 & & \\
\hline
\end{tabular}

A perda do NT na enxurrada do tratamento NPK, em relação à quantidade aplicada, foi de 4,8\%, excluída a contribuição do solo (Figura 1). Esse percentual de perda foi semelhante ao verificado por Favaretto (2002) que, trabalhando com chuva simulada aplicada sobre solo adubado com o equivalente a $180 \mathrm{~kg} \mathrm{ha}^{-1}$ de $\mathrm{N}$ solúvel, constatou que menos de $3 \%$ do fertilizante aplicado foi perdido. Já a perda de $\mathrm{N}$ na enxurrada do tratamento dejeto, em relação aos aplicados foi de 1,08\% (Figura 1). Considerando a quantidade de $\mathrm{N}$ total aplicado na forma de dejeto $\left(234 \mathrm{~kg} \mathrm{ha}^{-1}\right)$, poder-se-ia esperar um percentual de perda mais elevado nesse tratamento, uma vez que, segundo Sharpley et al. (1985), há uma relação entre a concentração de $\mathrm{N}$ na superfície do solo e a concentração de $\mathrm{N}$ na enxurrada. O comportamento destoante observado no presente trabalho em relação à afirmativa daqueles autores, provavelmente deve-se às diferenças na interação adubo/solo. O dejeto suíno por ser líquido infiltrou-se no solo, reduzindo a concentração do adubo na superfície. Além disso, o fato de que no dejeto suíno predomina o $\mathrm{N}$ na forma amoniacal, que é solúvel, podendo ser transportado e retido pelo solo em camadas mais profundas, ajudou a diminuir a disponibilidade do $\mathrm{N}$ para o transporte. Essas evidências permitem afirmar que adubos com condições diferentes de interação com o solo, quando aplicados na superfície, apresentam potencial diferente para o comprometimento da qualidade da água, sendo que, neste trabalho, o dejeto suíno apresentou um menor potencial em relação ao NPK.

As quantidades de $\mathrm{N}$ perdidas nas enxurradas das diferentes chuvas, em relação ao aplicado nos tratamentos D e NPK, foram bastante reduzidas. Na comparação entre tratamentos, verifica-se que os percentuais de perda do tratamento D foram muito inferiores aos percentuais do tratamento NPK (Figura 1). Essa diferença se torna ainda mais expressiva se for considerado que a quantidade aplicada nas parcelas do tratamento $\mathrm{D}\left(23,4 \mathrm{~g} \mathrm{~m}^{-2}\right.$ de $\left.\mathrm{N}\right)$ foi aproximadamente 38 vezes superior ao que foi aplicado no tratamento NPK $\left(0,62 \mathrm{~g} \mathrm{~m}^{-2}\right.$ de N). 


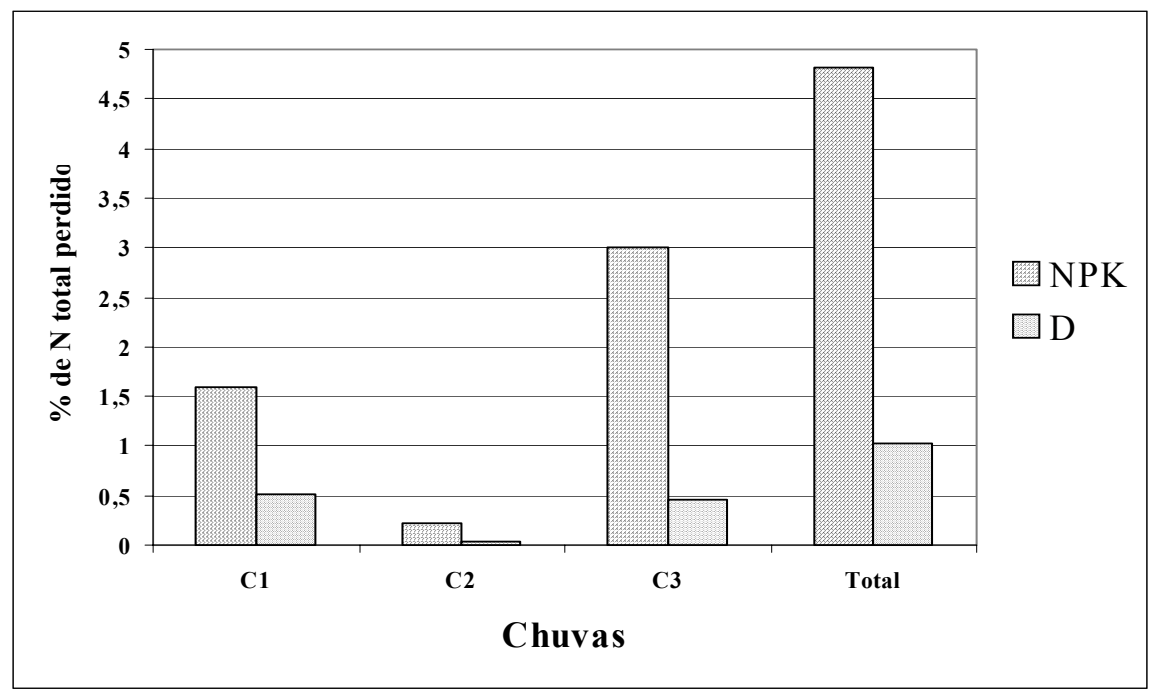

Figura 1. Percentagem de nitrogênio total (NT) perdido via enxurrada de três chuvas simuladas $(\mathrm{C} 1, \mathrm{C} 2$, C3), em relação ao total de nitrogênio aplicado nos tratamentos dejeto de suíno (D) e adubo mineral (NPK).

Figure 1. Percentage of total nitrogen (TN) lost by runoff of three simulated rainfall $(\mathrm{C} 1, \mathrm{C} 2, \mathrm{C} 3)$, as compared to the total nitrogen applied in the swine manure (D) and mineral fertilizer (NPK) treatments.

Concentração de nitrogênio total no sobrenadante da enxurrada

No sobrenadante da enxurrada, o tratamento com dejeto de suíno proporcionou uma concentração maior de NT na chuva $\mathrm{C} 1$, o que mostra que o dejeto suíno teve maior capacidade para fornecer $\mathrm{N}$ à porção sobrenadante da enxurrada na primeira chuva, em relação aos demais tratamentos (Tabela 3). No entanto, na chuva $\mathrm{C} 3$ os valores foram iguais entre os tratamentos. Isso pode ser explicado pela maior remoção de sedimentos grosseiros, que não permanecem suspensos no sobrenadante e, portanto, não contabilizam na concentração de $\mathrm{N}$ total, devido à maior intensidade da chuva, bem como $\mathrm{a}$ menor disponibilidade de $\mathrm{N}$ do dejeto, por ter sido removido pelas primeiras chuvas.

Tabela 3. Contraste de médias da concentração de $\mathrm{N}$ total no sobrenadante da enxurrada em três chuvas simuladas $(\mathrm{C} 1, \mathrm{C} 2, \mathrm{C} 3)$ aplicadas seqüencialmente nos tratamentos dejeto de suíno (D), adubo mineral (NPK) e testemunha (T).

Table 3: Mean contrast of the runoff supernatant total $\mathrm{N}$ concentration in three simulated rainfall $(\mathrm{C} 1$, C2, C3) sequentially applied on the swine manure (D), mineral fertilizer (NPK) and control (T) treatments.

\begin{tabular}{|c|c|c|c|c|c|}
\hline \multirow[t]{2}{*}{ Chuvas } & \multicolumn{3}{|c|}{ Tratamento } & \multicolumn{2}{|c|}{ Contrastes } \\
\hline & D & NPK & $\mathbf{T}$ & T vs D, NPK & D vs NPK \\
\hline & \multicolumn{3}{|c|}{ 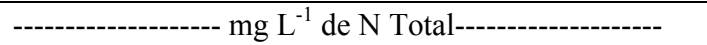 } & \multicolumn{2}{|c|}{$\operatorname{Pr}>\mathrm{F}$} \\
\hline $\mathrm{C} 1$ & $43,66 \pm 4,62$ & $29,39 \pm 0,72$ & $24,27 \pm 3,76$ & 0,0180 & 0,0170 \\
\hline $\mathrm{C} 2$ & nd & nd & nd & & \\
\hline $\mathrm{C} 3$ & $27,61 \pm 2,63$ & $19,96 \pm 3,76$ & $18,99 \pm 2,99$ & 0,2470 & 0,1210 \\
\hline Contrastes & & $\operatorname{Pr}>F$ & & & \\
\hline C1 vs C3 & 0,0270 & 0,0490 & 0,3140 & & \\
\hline
\end{tabular}

A seqüência de chuvas influenciou a concentração de NT no sobrenadante da enxurrada dos tratamentos D e NPK. Para os tratamentos D e NPK, a chuva C1 teve média superior a C3, indicando que a primeira chuva proporcionou um sobrenadante com maior concentração de NT, independentemente do 
adubo utilizado (Tabela 3). A relação entre as concentrações de NT no sobrenadante da enxurrada e na enxurrada apresentou valores que variam entre 0,65 e 0,83 . Os resultados permitem inferir que uma enxurrada formada em ambiente de lavoura conduzida sob o sistema de semeadura direta pode conter no sobrenadante uma concentração de NT elevada o suficiente para influenciar na qualidade da água dos rios situados a jusante do local de descarga da enxurrada.

\section{Concentração de amônio $\left(\mathrm{N}-\mathrm{NH}_{4}\right)$ solúvel na enxurrada}

As concentrações de $\mathrm{N}-\mathrm{NH}_{4}$ solúvel na enxurrada de todas as chuvas do tratamento $\mathrm{D}$ foram superiores aos demais tratamentos (Tabela 4), tendo valores mais elevados do que o índice máximo sugerido por USEPA (1973), citado por Sharpley et al. (1987), para garantir a qualidade da água que, segundo os autores, é de $0,5 \mathrm{mg} \mathrm{L}^{-1}$ para a saúde humana e de $2,5 \mathrm{mg} \mathrm{L}^{-1}$ para peixes.

Esses resultados se devem à grande disponibilidade $\mathrm{N}_{-} \mathrm{NH}_{4}$ no dejeto suíno, uma vez que aplicaram-se $234 \mathrm{~kg} \mathrm{ha}^{-1}$ de $\mathrm{N}$ total, e segundo Sullivan (1999), mais de 60\% do N total está na forma de $\mathrm{N}-\mathrm{NH}_{4}$. Assim, esses valores não foram ainda maiores provavelmente em decorrência dos seguintes fatores: a) infiltração do dejeto no solo durante o intervalo de tempo entre a sua colocação e a aplicação das chuvas; b) infiltração da água precipitada na chuva de umedecimento e no início da chuva $\mathrm{C}$, ocasionando a lixiviação de parte do $\mathrm{N}-\mathrm{NH}_{4}$; c) elevada disponibilidade do $\mathrm{N}_{-} \mathrm{NH}_{4}$ nativo na superfície do solo, uma vez que a semeadura direta permite concentrar na superfície do solo até seis vezes mais $\mathrm{N}_{-} \mathrm{NH}_{4}$, em relação ao sistema convencional (Laflen e Tabatabai, 1984); d) adsorção do $\mathrm{N}_{-} \mathrm{NH}_{4}$ pelo complexo de troca de cátions do solo (Sharpley et al., 1993). A sequência de chuvas não influenciou a concentração do $\mathrm{N}-\mathrm{NH}_{4}$ da enxurrada do tratamento $\mathrm{D}$, sendo que os valores mantiveram-se sempre elevados, com tendência de crescimento para as chuvas $\mathrm{C} 2$ e C3. Esses resultados mostraram que o dejeto de suíno teve condições de prolongar o fornecimento do $\mathrm{N}-\mathrm{NH}_{4}$, podendo potencializar a poluição da água por $\mathrm{N}-\mathrm{NH}_{4}$ em chuvas seqüenciais.

As baixas concentrações de $\mathrm{N}_{-} \mathrm{NH}_{4}$ nos tratamentos NPK e $\mathrm{T}$ seguramente refletem a baixa quantidade de N colocado no tratamento NPK e o fato de que, numa condição de solo natural, grande parte do $\mathrm{N}_{-} \mathrm{NH}_{4}$ encontra-se adsorvido pela CTC do solo (Sharpley et al., 1993).

Tabela 4. Contraste de médias da concentração de N-NH4 solúvel na enxurrada de três chuvas simuladas $(\mathrm{C} 1, \mathrm{C} 2, \mathrm{C} 3)$ aplicadas seqüencialmente nos tratamentos dejeto de suíno (D), adubo mineral (NPK) e testemunha (T).

Table 4. Mean contrast of the runoff soluble NH4-N concentration in three simulated rainfall $(\mathrm{C} 1, \mathrm{C} 2$, C3) sequentially applied on the swine manure (D), mineral fertilizer (NPK) and control (T) treatments.

\begin{tabular}{|c|c|c|c|c|c|}
\hline \multirow{2}{*}{ Chuvas } & \multicolumn{3}{|c|}{ Tratamento } & \multicolumn{2}{|c|}{ Contrastes } \\
\hline & D & NPK & $\mathbf{T}$ & T vs D, NPK & D vs NPK \\
\hline & \multicolumn{3}{|c|}{------------- $\left(\mathrm{mg} \mathrm{L}^{-1}\right) \mathrm{N}-\mathrm{NH}_{4}$ Solúvel ------------- } & \multicolumn{2}{|c|}{$\operatorname{Pr}>\mathrm{F}$} \\
\hline $\mathrm{C} 1$ & $3,25 \pm 0,77$ & $0,211 \pm 0,39$ & $0,012 \pm 0,003$ & 0,0020 & 0,0009 \\
\hline $\mathrm{C} 2$ & $5,084 \pm 0,82$ & $0,312 \pm 0,09$ & $0,032 \pm 0,007$ & 0,0013 & $<0,0001$ \\
\hline $\mathrm{C} 3$ & $4,989 \pm 0,37$ & $0,188 \pm 0,04$ & $0,007 \pm 0,001$ & $<0,0001$ & $<0,0001$ \\
\hline Contrastes & & $\operatorname{Pr}>\mathrm{F}$ & & & \\
\hline $\mathrm{C} 1$ vs $\mathrm{C} 2, \mathrm{C} 3$ & 0,0610 & 0,6430 & 0,2190 & & \\
\hline $\mathrm{C} 2$ vs $\mathrm{C} 3$ & 0,9240 & 0,2040 & 0,0040 & & \\
\hline
\end{tabular}

\section{Concentração de nitrato $\left(\mathrm{N}-\mathrm{NO}_{3}\right)$ solúvel na enxurrada}

A concentração de nitrogênio na forma de $\mathrm{N}_{-} \mathrm{NO}_{3}$ na enxurrada do tratamento $\mathrm{D}$ também foi superior aos demais tratamentos (Tabela 5). Embora no dejeto suíno predomine o $\mathrm{N}$ na forma de $\mathrm{N}-\mathrm{NH}_{4}$, parte do $\mathrm{N}$ total poderia estar na forma de $\mathrm{N}_{-} \mathrm{NO}_{3}$, uma vez que, em condições de clima quente e úmido, o processo de nitrificação do $\mathrm{N}$ orgânico é acelerado. No entanto, os valores de $\mathrm{N}_{-} \mathrm{NO}_{3}$ desse tratamento foram inferiores ao limite máximo de contaminação para água de consumo humano estabelecido tanto no Brasil como nos Estados Unidos da América, que é de $10 \mathrm{mg} \mathrm{L}^{-1}$ de $\mathrm{N}_{-\mathrm{NO}_{3}}$ (Tundisi, 2003; USEPA, 1986). A concentração de $\mathrm{N}-\mathrm{NO}_{3}$ na enxurrada do tratamento $\mathrm{D}$ não foi maior devido provavelmente à 
infiltração do dejeto no solo durante o intervalo de tempo entre a sua colocação na parcela e a aplicação das chuvas, bem como à chuva de umedecimento, ocasionando a lixiviação do $\mathrm{N}-\mathrm{NO}_{3}$, diante da sua baixa reatividade.

Tabela 5. Contraste de médias da concentração de N-NO3 solúvel na enxurrada de três chuvas simuladas (C1, C2, C3) aplicadas seqüencialmente nos tratamentos dejeto de suíno (D), adubo mineral (NPK) e testemunha (T).

Table 5. Mean contrast of the runoff soluble NO3-N concentration in three simulated rainfall $(\mathrm{C} 1, \mathrm{C} 2$, C3) sequentially applied on the swine manure (D), mineral fertilizer (NPK) and control (T) treatments.

\begin{tabular}{|c|c|c|c|c|c|}
\hline \multirow{2}{*}{ Chuvas } & \multicolumn{3}{|c|}{ Tratamento } & \multicolumn{2}{|c|}{ Contrastes } \\
\hline & D & NPK & $\mathbf{T}$ & T vs D, NPK & D vs NPK \\
\hline & \multicolumn{3}{|c|}{------------- $\left(\mathrm{mg} \mathrm{L}^{-1}\right) \mathrm{N}^{-\mathrm{NO}_{3}}$ Solúvel ------------- } & \multicolumn{2}{|c|}{$\operatorname{Pr}>\mathrm{F}$} \\
\hline $\mathrm{C} 1$ & $3,05 \pm 0,32$ & $1,817 \pm 0,49$ & $1,124 \pm 0,13$ & 0,0130 & 0,0330 \\
\hline $\mathrm{C} 2$ & $2,492 \pm 0,21$ & $0,852 \pm 0,26$ & $0,422 \pm 0,10$ & 0,0007 & 0,0003 \\
\hline $\mathrm{C} 3$ & $2,266 \pm 0,25$ & $1,253 \pm 0,41$ & $0,266 \pm 0,08$ & 0,0020 & 0,0290 \\
\hline Contrastes & & $\operatorname{Pr}>F$ & & & \\
\hline $\mathrm{C} 1$ vs $\mathrm{C} 2, \mathrm{C} 3$ & 0,0680 & 0,1480 & 0,0002 & & \\
\hline $\mathrm{C} 2$ vs $\mathrm{C} 3$ & 0,5610 & 0,5150 & 0,2250 & & \\
\hline
\end{tabular}

Pr $>$ F: p-valor da estatística F para contrastes ortogonais.

A concentração de $\mathrm{N}^{-\mathrm{NO}_{3}}$ na enxurrada do tratamento NPK foi superior à concentração no tratamento $\mathrm{T}$ (Tabela 5). No entanto, esses valores podem ser considerados baixos em relação ao limite de $10 \mathrm{mg} \mathrm{L}^{-1}$. Comparativamente ao $\mathrm{N}-\mathrm{NH}_{4}$, as concentrações do $\mathrm{N}-\mathrm{NO}_{3}$ foram superiores nos tratamentos NPK e T, seguramente devido à elevada disponibilidade do $\mathrm{N}-\mathrm{NO}_{3}$ em condições naturais na superfície do solo e por ser facilmente removido pela água da chuva em razão de ser fracamente retido pelas partículas ativas do solo (Sharpley et al., 1993). Embora as concentrações de $\mathrm{N}^{-\mathrm{NO}_{3}}$ na enxurrada de todos os tratamentos tenham sido inferiores ao limite de $10 \mathrm{mg} \mathrm{L}^{-1}$, deve-se considerar que o menor valor do NT na enxurrada de todos o três tratamentos foi em torno de três vezes o valor do índice. Como as formas de nitrogênio orgânico e amoniacal podem ser convertidas em nitrato por algumas espécies de microorganismos (Branco, 1986), então pode-se considerar que nessas condições a enxurrada é uma fonte potencial de contaminação da água pelo $\mathrm{N}-\mathrm{NO}_{3}$.

Ao contrário do que ocorreu na concentração do NT na enxurrada e no sobrenadante, as chuvas não exerceram influência na concentração do $\mathrm{N}-\mathrm{NH}_{4}$ e do $\mathrm{N}-\mathrm{NO}_{3}$ solúvel na enxurrada. Esses resultados contrariam os obtidos por Favaretto (2002), que registrou as maiores perdas desses elementos no início das chuvas. No entanto, as diferenças podem ser atribuídas ao fato de que o presente trabalho foi realizado em solo manejado através de semeadura direta, numa condição de sistema já estabilizado, onde há acúmulo de nutrientes, em especial $\mathrm{N}$ em diferentes formas na superfície do solo (Laflen e Tabatabai, 1984; Heathwaite et al., 2000). Essas condições se mostraram capazes de sustentar iguais quantidades de $\mathrm{N}-\mathrm{NH}_{4}$ e $\mathrm{N}-\mathrm{NO}_{3}$ para a enxurrada de todas as chuvas.

A participação do nitrogênio particulado $\left(\mathrm{N}\right.$ total menos $\left.\mathrm{N}-\mathrm{NH}_{4}\right)$ no $\mathrm{N}$ total $(\mathrm{NP} / \mathrm{NT})$ foi acentuadamente maior do que a participação do nitrogênio solúvel $\left(\mathrm{N}-\mathrm{NH}_{4}\right.$ solúvel mais $\mathrm{N}_{-} \mathrm{NO}_{3}$ solúvel) no nitrogênio total (NS/NT), tendo alcançado quase 100\% nos tratamentos NPK e T (Figura 2). Embora a semeadura direta seja um meio eficiente no controle das perdas de solo (Laflen e Tabatabai, 1984; Eghball e Gilley, 1999; Soileau et al., 1994), os resultados demonstram que ocorreu uma perda substancial de sedimentos, de tal forma que responderam pela maior parte do $\mathrm{N}$ total perdido. Verifica-se ainda que em condições de solo natural essa participação foi mais expressiva do que quando foi usado fertilizante. Sharpley et al. (1987) constataram que $64 \%$ do $N$ total na água vinda de bacias hidrográficas estudadas se constituíam de $\mathrm{N}$ particulado. Para os valores elevados obtidos nesse trabalho, certamente contribuiu a mobilização do solo proporcionada pela operação de semeadura antes da aplicação das chuvas.

A participação do $\mathrm{N}$ solúvel no $\mathrm{N}$ total (Figura 2) foi pouco expressiva, em especial nos tratamentos NPK e T, por decorrência natural da elevada quantidade de N associado aos sedimentos. 
Entre os tratamentos, os percentuais mais elevados de $\mathrm{N}$ solúvel no $\mathrm{N}$ total ocorreram no tratamento D. Esses resultados provavelmente ocorreram mais em função da maior dose de $\mathrm{N}$ aplicado do que pela fonte de fertilizante mineral. A quantidade de $\mathrm{N}$ aplicado ao solo no tratamento $\mathrm{D}$ foi aproximadamente 38 vezes superior ao aplicado no tratamento NPK

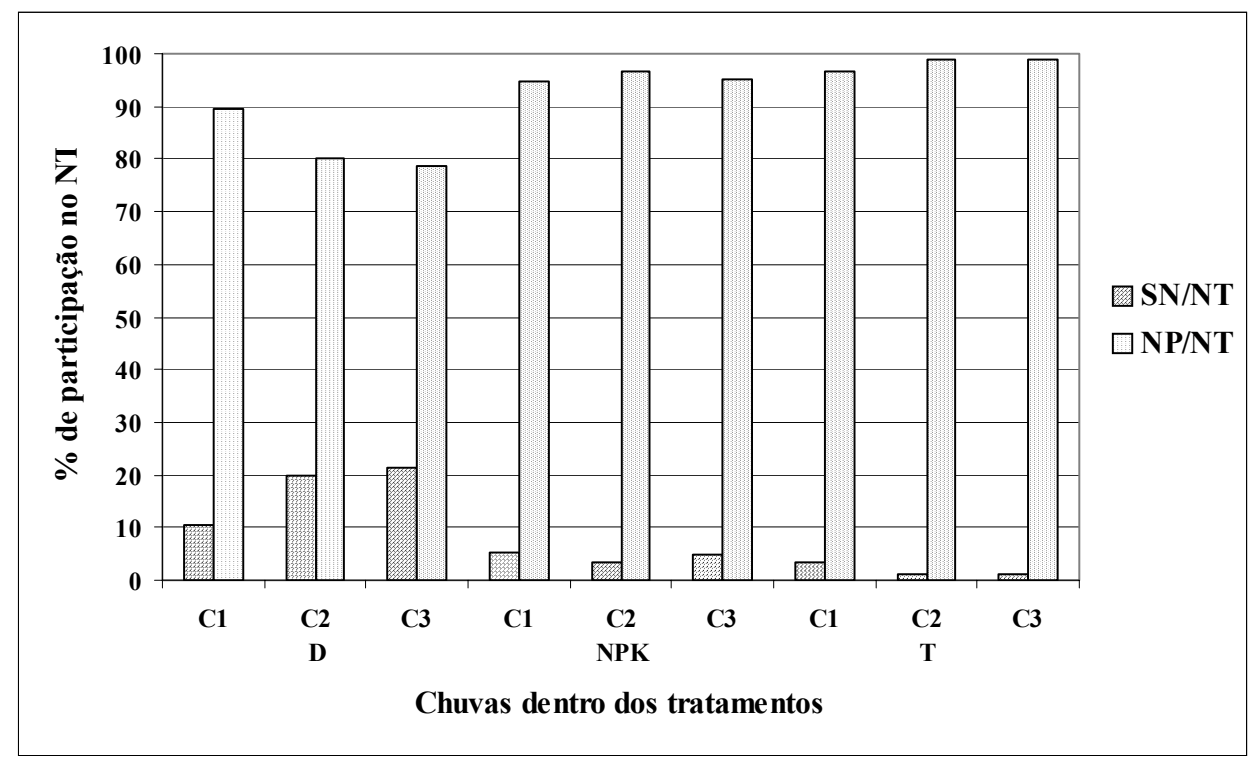

Figura 2. Percentagem do nitrogênio particulado e do nitrogênio solúvel no nitrogênio total (NP/NT e NS/NT) da enxurrada de três chuvas simuladas $(\mathrm{C} 1, \mathrm{C} 2, \mathrm{C} 3)$ aplicadas seqüencialmente nos tratamentos dejeto de suíno (D), adubo mineral (NPK) e testemunha (T).

Figure 2. Percentage of the runoff particulate and soluble nitrogen in the total nitrogen (PN/TN and $\mathrm{SN} / \mathrm{TN})$ in three simulated rainfall $(\mathrm{C} 1, \mathrm{C} 2, \mathrm{C} 3)$ sequentially applied on the swine manure (D), mineral fertilizer (NPK) and control (T) treatments.

\section{Retenção de $\mathrm{N}_{-} \mathrm{NO}_{3}$ e $\mathrm{N}-\mathrm{NH}_{4}$ pela matriz do solo}

Concentração de nitrato na água percolada

A água percolada pelas colunas de solo apresentou concentrações de $\mathrm{N}_{-} \mathrm{NO}_{3}$ superiores no tratamento NPK em relação aos outros dois tratamentos em todos os turnos (Tabela 6). Nesse tratamento, pode-se dizer que não houve retenção do $\mathrm{N}_{-} \mathrm{NO}_{3}$ pela matriz do solo, uma vez que ocorreu a lixiviação de quase $100 \%$ do elemento aplicado na superfície. O total de $\mathrm{N}-\mathrm{NO}_{3}$ presente na água percolada de todos os turnos foi $0,1659 \mathrm{~g}$, e a quantidade aplicada foi $0,1684 \mathrm{~g}$. Resultados semelhantes foram obtidos por Favaretto (2002), que registrou uma quantidade de $\mathrm{N}-\mathrm{NO}_{3}$ lixiviada superior à aplicada. A autora atribuiu os resultados à existência no solo de uma quantidade já substancial do elemento na forma nativa. Diante das características do solo utilizado para este trabalho, que era de textura argilosa e com mineralogia predominante de caulinita e hematita, esperava-se maior retenção de $\mathrm{N}_{-} \mathrm{NO}_{3}$ na matriz do solo, uma vez que solos com essa mineralogia apresentam CTA. A grande perda de nitrato observada neste experimento pode ser devido à baixa adsorção pelo solo, bem como à sua elevada concentração em condições naturais no solo, o que pode ser observada pela sua alta concentração no tratamento T (Tabela 6). Os menores valores de $\mathrm{N}_{-} \mathrm{NO}_{3}$ obtidos no tratamento D podem ser explicados pela baixa concentração desse elemento no dejeto suíno, já que nesse tipo de adubo predomina o $\mathrm{N}-\mathrm{NH}_{4}$. Os tratamentos $\mathrm{D}$ e $\mathrm{T}$ diferiram pouco entre si em todos os turnos, mostrando o baixo potencial poluidor de nitrato pela aplicação de dejeto de suíno.

A análise da concentração do $\mathrm{N}-\mathrm{NO}_{3}$ na água percolada em relação à seqüência dos turnos mostra que no tratamento NPK os valores foram iguais nos três primeiros turnos, reduzindo-se nos dois últimos, que foram iguais entre si. Já o tratamento $\mathrm{T}$ apresentou, nos três primeiros turnos, uma concentração maior do que os últimos dois, os quais também foram iguais. Os resultados mostram que, 
quando foi usado adubo mineral prontamente solúvel, o processo de perda do $\mathrm{N}^{-\mathrm{NO}_{3}}$ foi bastante rápido, já que em torno de $75 \%$ do elemento aplicado foi perdido no primeiro volume de poros. Verifica-se ainda que, no solo em condições naturais (tratamento T), as perdas também foram elevadas no início do processo de percolação da água, o que pode ser um reflexo da grande disponibilidade do $\mathrm{N}^{-\mathrm{NO}_{3}} \mathrm{em}$ sistemas de manejo do solo sob semeadura direta. Favaretto (2002) encontrou resultados semelhantes, uma vez que todo o $\mathrm{N}^{-\mathrm{NO}_{3}}$ por ela aplicado na superfície das colunas de solo foi lixiviado pela água percolada nos dois primeiros volumes de poros. $\mathrm{O}$ tratamento $\mathrm{D}$ apresentou comportamento distinto dos demais tratamentos, uma vez que o turno T1A teve menor concentração de $\mathrm{N}_{-} \mathrm{NO}_{3}$ do que o turno T1B, que por sua vez teve valores maiores do que os demais turnos. Isso provavelmente ocorreu devido à lenta solubilização do $\mathrm{N}-\mathrm{NO}_{3}$ no dejeto suíno e à capacidade dos compostos orgânicos em reter parte do $\mathrm{N}^{-\mathrm{NO}_{3}}$ existente no solo no início do processo de percolação. Isso pode também explicar a tendência de menor concentração no turno T1A desse tratamento em relação ao mesmo turno do tratamento T.

Tabela 6. Contraste de médias da concentração de N-NO3 solúvel lixiviado em cinco turnos de água percolada (T1A, T1B, T1C, T2, T3) aplicados seqüencialmente nos tratamentos dejeto de suíno (D), adubo mineral (NPK) e testemunha (T).

Table 6. Mean contrast of the soluble NO3-N concentration in five leaching (T1A, T1B, T1C, T2, T3) sequentially applied on the swine manure (D), mineral fertilizer (NPK) and control (T) treatments.

\begin{tabular}{|c|c|c|c|c|c|}
\hline \multirow{2}{*}{ Turnos } & \multicolumn{3}{|c|}{ Tratamentos } & \multicolumn{2}{|c|}{ Contrastes } \\
\hline & D & NPK & $\mathbf{T}$ & T vs D, NPK & D vs NPK \\
\hline & \multicolumn{3}{|c|}{ 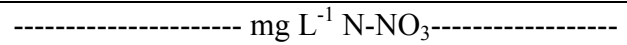 } & \multicolumn{2}{|c|}{$\operatorname{Pr}>\mathrm{F}$} \\
\hline T1A & $15,33 \pm 0,31$ & $66,54 \pm 5,60$ & $24,73 \pm 2,00$ & 0,0040 & $<0,0001$ \\
\hline T1B & $22,89 \pm 3,46$ & $54,55 \pm 4,88$ & $25,43 \pm 2,69$ & 0,0190 & 0,0002 \\
\hline $\mathrm{T} 1 \mathrm{C}$ & $13,36 \pm 2,33$ & $55,10 \pm 4,68$ & $13,34 \pm 2,16$ & 0,0010 & $<0,0001$ \\
\hline $\mathrm{T} 2$ & $3,44 \pm 0,16$ & $15,82 \pm 1,63$ & $8,62 \pm 1,93$ & 0,5870 & 0,0002 \\
\hline $\mathrm{T} 3$ & $1,92 \pm 0,25$ & $7,94 \pm 0,82$ & $3,05 \pm 0,60$ & 0,0320 & $<0,0001$ \\
\hline Contrastes & & $\operatorname{Pr}>\mathrm{F}$ & & & \\
\hline T1A, T1B, T1C vs T2, T3 & $<0,0001$ & $<0,0001$ & $<0,0001$ & & \\
\hline T1A vs T1B, T1C & 0,0120 & 0,0520 & 0,8080 & & \\
\hline T1B vs T1C & 0,0030 & 0,9240 & 0,0007 & & \\
\hline T2 vs T3 & 0,5750 & 0,1850 & 0,0680 & & \\
\hline
\end{tabular}

Pr $>$ F: p-valor da estatística F para contrastes ortogonais.

Pode-se observar que a concentração de $\mathrm{N}-\mathrm{NO}_{3} \mathrm{em}$ todos os tratamentos no primeiro volume de poros (T1A, T1B e T1C) esteve acima do valor máximo permitido $\left(10 \mathrm{mg} \mathrm{L}^{-1}\right.$ de $\left.\mathrm{N}-\mathrm{NO}_{3}\right)$ pela legislação brasileira em água de consumo humano, bem como em cursos de água doce de classe 1,2 e 3 (Tundisi, 2003; BRASIL, 1986). No entanto, o potencial poluidor do adubo mineral é superior quando comparado com o uso de dejeto de suínos.

\section{Concentração de amônio na água percolada}

A concentração de $\mathrm{N}^{-\mathrm{NH}_{4}}$ na água percolada teve comportamento semelhante ao do $\mathrm{N}-\mathrm{NO}_{3}$. O tratamento NPK apresentou médias superiores em relação aos outros dois tratamentos nos turnos iniciais (T1A, T1B e T1C) (Tabela 7). Todavia, nos últimos dois turnos as concentrações passaram a ser menores do que as do tratamento $\mathrm{D}$, mas continuaram superiores às do tratamento $\mathrm{T}$. Com relação ao tratamento NPK, os resultados mostram que a matriz do solo foi capaz de reter em torno de $80 \%$ do $\mathrm{N}^{-N_{4}}$, provavelmente devido a: a) uma elevada CTC presente no solo, em razão da mineralogia e do elevado teor de matéria orgânica acumulada nas camadas superficiais do solo; b) o poder reativo do $\mathrm{N}^{-\mathrm{NH}_{4}}$, facilitando a sua adsorção pelos compostos orgânicos e minerais do solo. Na comparação entre os tratamentos D e NPK, considerando-se a aplicação de $660 \mathrm{~kg} \mathrm{ha}^{-1}$ de N total na forma de dejeto e $140 \mathrm{~kg}$ $\mathrm{ha}^{-1}$ de $\mathrm{N}$ na forma de adubo mineral solúvel, poder-se-ia esperar uma concentração bem maior desse elemento na água percolada do tratamento $\mathrm{D}$, uma vez que, como já citado, grande parte do $\mathrm{N}$ no dejeto 
suíno encontra-se na forma de $\mathrm{N}-\mathrm{NH}_{4}$. No entanto, a menor perda no tratamento com dejeto suíno pode ser explicada pela capacidade que as frações orgânicas presentes nesse têm de adsorver íons, em especial aqueles mais reativos, como o amônio. Assim, ao penetrar no solo, essas frações orgânicas podem reter o $\mathrm{N}-\mathrm{NH}_{4}$, inclusive aquele nativo do solo, resultando em uma baixa concentração do elemento na solução do solo (Kleinman et al., 2003). Todos os turnos do tratamento T tiveram baixas concentrações de $\mathrm{N}^{-\mathrm{NH}_{4}}$, refletindo a retenção desse elemento pela CTC do solo em condições naturais, o que dificulta a sua solubilização.

Tabela 7. Contraste de médias da concentração de N-NH4 solúvel lixiviado em cinco turnos de água percolada (T1A, T1B, T1C, T2, T3) aplicados seqüencialmente nos tratamentos dejeto de suíno (D), adubo mineral (NPK) e testemunha (T).

Table 7. Mean contrast of the soluble NH4-N concentration in five leaching (T1A, T1B, T1C, T2, T3) sequentially applied on the swine manure (D), mineral fertilizer (NPK) and control (T) treatments.

\begin{tabular}{|c|c|c|c|c|c|}
\hline \multirow{2}{*}{ Turnos } & \multicolumn{3}{|c|}{ Tratamentos } & \multicolumn{2}{|c|}{ Contrastes } \\
\hline & D & NPK & $\mathbf{T}$ & T vs D, NPK & D vs NPK \\
\hline & \multicolumn{3}{|c|}{ - } & \multicolumn{2}{|c|}{$\operatorname{Pr}>\mathrm{F}$} \\
\hline T1A & $0,74 \pm 0,08$ & $16,45 \pm 0,99$ & $0,07 \pm 0,06$ & $<0,0001$ & $<0,0001$ \\
\hline T1B & $5,62 \pm 0,68$ & $8,34 \pm 0,62$ & $0,011 \pm 0,002$ & $<0,0001$ & 0,0060 \\
\hline $\mathrm{T} 1 \mathrm{C}$ & $3,20 \pm 0,35$ & $5,15 \pm 0,55$ & $0,101 \pm 0,04$ & $<0,0001$ & 0,0050 \\
\hline $\mathrm{T} 2$ & $4,44 \pm 0,24$ & $2,61 \pm 0,24$ & $0,015 \pm 0,001$ & $<0,0001$ & $<0,0001$ \\
\hline T3 & $4,22 \pm 0,64$ & $1,35 \pm 0,23$ & $0,005 \pm 0,001$ & 0,0003 & 0,0006 \\
\hline Contrastes & & $\operatorname{Pr}>\mathrm{F}$ & & & \\
\hline T1A, T1B, T1C vs T2, T3 & 0,0120 & $<0,0001$ & 0,0980 & & \\
\hline T1A vs T1B, T1C & $<0,0001$ & $<0,0001$ & 0,2040 & & \\
\hline T1B vs T1C & 0,0020 & 0,0020 & 0,0640 & & \\
\hline T2 vs T3 & 0,7500 & 0,1570 & 0,8340 & & \\
\hline
\end{tabular}

$\operatorname{Pr}>$ F: p-valor da estatística F para contrastes ortogonais.

A comparação da concentração do $\mathrm{N}-\mathrm{NH}_{4}$ entre turnos mostra que os tratamentos tiveram comportamento semelhante ao do $\mathrm{N}_{-\mathrm{NO}_{3}}$, exceto no tratamento $\mathrm{T}$. Nesse tratamento, as concentrações de $\mathrm{N}-\mathrm{NH}_{4}$ não diferiram entre os turnos. A baixa concentração de $\mathrm{N}^{-\mathrm{NH}_{4}}$ observada no turno T1A do tratamento $\mathrm{D}$ pode significar que o dejeto suíno tem a capacidade de diminuir a lixiviação desse elemento nos momentos iniciais da percolação da água. Já nos demais turnos, os valores se mantiveram quase inalterados, indicando que a presença do dejeto suíno proporciona também o prolongamento do potencial de lixiviação do $\mathrm{N}_{-} \mathrm{NH}_{4}$. No tratamento NPK, observa-se que o uso de $\mathrm{N}-\mathrm{NH}_{4}$ na forma de adubo químico solúvel contribuiu para um processo mais rápido de perda desse elemento, uma vez que em torno de $70 \%$ do $\mathrm{N}^{-\mathrm{NH}_{4}}$ aplicado foi perdido no primeiro volume de poros.

Quanto à retenção do $\mathrm{N}-\mathrm{NH}_{4}$ e N-NO 3 pela matriz do solo no processo de percolação da água, é necessário considerar que a camada de solo utilizada $(20 \mathrm{~cm})$ corresponde à porção arável do solo, que, por ser indeformada e por ter sido retirada em área de semeadura direta, pode apresentar naturalmente certa quantidade de bioporos. Os bioporos são macroporos na sua maioria, produzidos principalmente pelas raízes das plantas e organismos do solo, o que dá a eles uma boa continuidade e conectividade, resultando no transporte via fluxo preferencial (Heathwaite et al., 2000). A água que percola pelos bioporos tem um rápido contato com o solo, podendo arrastar consigo elementos minerais e orgânicos sem que sejam retidos na matriz do solo. Essa condição possibilita um rápido enriquecimento da água percolada (Jensen et al., 1998). No entanto, considerando que os solos, em especial os latossolos, apresentam profundidade muito superior a $20 \mathrm{~cm}$, a capacidade de retenção de nutrientes, mesmo no caso daqueles com alto potencial de lixiviação, se eleva substancialmente. Rizzi (1991) ao aplicar água de esgoto urbano em colunas indeformadas de solo de diferentes alturas, constatou que as colunas com 30 $\mathrm{cm}$ de altura tiveram uma eficiência mínima na retenção de $\mathrm{N}^{-N_{4}}$ de $34,1 \%$, enquanto que em colunas de $150 \mathrm{~cm}$ a eficiência foi de $99,5 \%$. 


\section{CONCLUSÕES}

Independentemente da fonte de fertilizante, a concentração do $\mathrm{N}$ total, tanto na enxurrada quanto no sobrenadante da enxurrada, foi maior na chuva inicial do que na chuva final, mesmo tendo sido esta a de maior intensidade. No entanto, o dejeto líquido de suíno, quando comparado aos demais tratamentos, propiciou uma maior concentração de $\mathrm{N}$ total na enxurrada, com exceção da chuva de menor intensidade.

$\mathrm{O}$ uso de dejeto líquido de suíno resultou na maior concentração tanto de $\mathrm{N}^{-\mathrm{NH}_{4}}$ quanto de $\mathrm{N}$ $\mathrm{NO}_{3}$ dissolvidos na enxurrada em todas as chuvas simuladas, estando esses resultados de acordo com a maior aplicação de $\mathrm{N}$ total. Porém, na água percolada, em todos os volumes de poros, observou-se o inverso: uma maior concentração tanto de $\mathrm{N}-\mathrm{NH}_{4}$ quanto de $\mathrm{N}-\mathrm{NO}_{3}$ no tratamento com fertilizante mineral, embora a quantidade de $\mathrm{N}$ total aplicada nesse tratamento fosse inferior ao aplicado no dejeto líquido de suínos.

A matriz do solo mostrou-se mais eficiente em reter $\mathrm{N}-\mathrm{NH}_{4}$ do que $\mathrm{N}_{-} \mathrm{NO}_{3}$. Para o fertilizante mineral, a retenção do $\mathrm{N}-\mathrm{NH}_{4}$ foi de aproximadamente $80 \%$ em relação ao aplicado, enquanto que $100 \%$ do $\mathrm{N}_{-} \mathrm{NO}_{3}$ aplicado foi lixiviado.

\section{BIBLIOGRAFIA}

AMARAL, A. S. Mecanismos de correção da acidez do solo no sistema de plantio direto com aplicação de calcário na superfície. Porto Alegre, 2002. 107 f. Tese (Doutorado) - Universidade Federal do Rio Grande do Sul.

AMERICAN PUBLIC HEALTH ASSOCIATION. Standard methods of the examination of water and wastewater. Washington, DC, 1995.

BRANCO, S. M. A Água como meio ecológico. In: Hidrologia aplicada à engenharia sanitária. São Paulo: CETESB,1986. p. 121-166.

BRASIL. Conselho Nacional do Meio Ambiente. Resolução número 20. Diário Oficial da União, Brasília, DF, 30 jul. 1986.

BREMNER, J. M. Nitrogen-total. In: SPARKS , D.L. et al. Methods of soil analysis: Part 3-chemical methods. Madison, WI: SSSA, 1996. p. 1085-1124. (Book Ser. 5.)

CASSOL, E. A.; LEVIEN, R.; ANGHINONI, I.; BADELUCCI, M. P. Perdas de nutrientes por erosão em diferentes métodos de melhoramento de pastagem nativa no Rio Grande do Sul. Revista Brasileira de Ciência do Solo, Campinas,n. 26, p. 705-712, 2002.

CORRELL, D. L. The role of phosphorus in the eutrofication of receiving waters. Journal of Environmental Quality, Madison, Wis., n. 27, p. 261-266, 1998.

DANIEL, T. C.; SHARPLEY, A. N.; LEMUNYON, J. L. Agricultural phosphorus and eutrofication: a symposium overview. Journal of Environmental Quality, Madison, Wis.,, n. 27, p. 251-257, 1998.

EMBRAPA. Centro Nacional de Pesquisa de Solos-CNPS. Manual de métodos de análise de solo. 2 ed. Rio de Janeiro. 1997. 212 p. (Embrapa-CNPS. Documentos, 01).

EGHBALL, B.; GILLEY, J. E. Phosphorus and nitrogen in runoff following beef cattle manure or compost application to no-till and tilled soil. Journal of Environmental Quality, Madison, Wis., n.28, p. 1201-1210, 1999.

FAVARETTO, N. Gypsum amendment and exchangeable calcium and magnesium related to water quality and plant nutrition. West Lafayette, IN, USA, 2002. 150f. Tese (Doutorado) - Purdue University.

GBUREK, W. J.; SHARPLEY, A. L. Hydrologic controls on phosphorus loss from upland agricultural watersheds. Journal of Environmental Quality, Madison, Wis., n. 27, p. 267-277, 1998. 
HEATHWAITE, A. L.; SHARPLEY, A. L.; GBUREK, W. J. A conceptual approach for integrating phosphorus and nitrogen management at watershed scale. Journal of Environmental Quality, Madison, Wis., n. 29, p. 158-166, 2000.

ISMAIL, I.; BLEVINS, R. L.; FRYE, W. W. Long-term no-tillage effects on soil properties and continuous corn yields. Soil Science Society Of America Journal, Madison, Wis., n. 58, p. 193-198, 1994.

JENSEN, M. B.; JORGENSEN, P. R.; HANSEN, H. C. B.; NIELSEN, N. E. Biopore mediated subsurface transport of dissolved orthophosphate. Journal of Environmental Quality, Madison, Wis., $\mathrm{n}$. 27, p. 1130-1137, 1998.

LAFLEN, J. M.; TABATABAI, M. A. Nitrogen and phosphorus losses from corn-soybean rotations as affected by tillage practices. Transactions of the ASAE, Saint. Joseph, Mich., v.27, p.58-63, 1984.

KLEINMAN, P. J. A.; NEEDELMAN, B. A.; SHARPLEY, A. N.; McDOWELL, R. W. Using soil phosphorus profile date to assess phosphorus potential in manured soil. Soil Science Society Of America Journal, Madison, Wis., n. 67, p. 215-224, 2003.

MEHRA, O. P.; JACKSON, M. L. Iron oxide removal from soils and clay by a dithionite-citrate system buffered with sodium bicarbonate. Clay Minerals, London, n. 7, p. 317-327, 1960.

MELO, V. F. Potássio e magnésio em minerais de solo e relação entre propriedades da caulinita com formas não trocáveis destes nutrientes. Viçosa, MG, 1998. 205p. Tese (Doutorado) - Universidade Federal de Viçosa.

MEYER, L. D.; WISCHMEIER, W. C.; FOSTER, G. R. Mulch rates required for erosion control on steep slopes. . Soil Science Society Of America Proceedings, Madison, Wis., n. 34, p. 928-931, 1970.

MIYAZAWA, M; PAVAN, M. A; BLOCK, M. F. M. Determinação espectrofotométrica de nitrato em extratos de solo sem redução química. Pesquisa Agropecuária, Brasília, DF, n. 20, p. 129-133, 1985.

NORMAN, R. J; STUCKI, J. W. The determination of nitrate and nitrate in soil extracts by ultraviolet spectrophotometry. Soil Science Society Of America Journal, Madison, Wis., n. 45, p. 347-353, 1981.

OWENS, L. B. Impacts of soil N management on the quality of surface and subsurface water. In: LAL ,R.; STEWART, B.A. (Eds.). Soil process and water quality: advances in soil science.Boca Raton: Lewis, 1994. p. 137-162.

PAVAN, M. A.; BLOCH, M. DE F.; ZEMPULSKI, H. DA C.; MIYAZAWA, M.; ZOCOLER, D. C. Manual de análise química de solo e controle de qualidade. Londrina: IAPAR, 1992. 39 p. (Circular n.76).

POTE, D. H.; DANIEL, D. J.; NICHOLS, A. N.; SHARPLEY, A. N.; MOORE, P. A. JR.; MILLER, D. M.; DWARDS, D. R Relationship between phosphorus levels in three ultisols and phosphorus concentrations in runoff. Journal of Environmental Quality, Madison, Wis., n. 28, p. 170-175, 1999.

RIZZI, N. E. Aplicacional de agua residual urbana en sedimentos de suelo florestal arcilloso: estudio experimental. Cantabria, Espanha, 1991. 275 f. Tese (Doutorado) - Universidad de Cantabria. 